\title{
Microstructural Characterization and Mechanical Properties of Ti-6Al-4V Alloy Subjected to Dynamic Plastic Deformation Achieved by Multipass Hammer Forging with Different Forging Temperatures
}

\author{
Xiurong Fang $\mathbb{D}$, Jiang $W u$, Xue Ou, and Fuqiang Yang $\mathbb{1}$ \\ School of Mechanical Engineering, Xi'an University of Science and Technology, Xi'an 710054, China \\ Correspondence should be addressed to Xiurong Fang; fangxr098@163.com
}

Received 29 March 2019; Revised 1 July 2019; Accepted 8 August 2019; Published 27 August 2019

Guest Editor: Rezwanul Haque

Copyright (C) 2019 Xiurong Fang et al. This is an open access article distributed under the Creative Commons Attribution License, which permits unrestricted use, distribution, and reproduction in any medium, provided the original work is properly cited.

Dynamic plastic deformation (DPD) achieved by multipass hammer forging is one of the most important metal forming operations to create the excellent materials properties. By using the integrated approaches of optical microscope and scanning electron microscope, the forging temperature effects on the multipass hammer forging process and the forged properties of Ti$6 \mathrm{Al}-4 \mathrm{~V}$ alloy were evaluated and the forging samples were controlled with a total height reduction of $50 \%$ by multipass strikes from $925^{\circ} \mathrm{C}$ to $1025^{\circ} \mathrm{C}$. The results indicate that the forging temperature has a significant effect on morphology and the volume fraction of primary $\alpha$ phase, and the microstructural homogeneity is enhanced after multipass hammer forging. The alloy slip possibility and strain rates could be improved by multipass strikes, but the marginal efficiency decreases with the increased forging temperature. Besides, a forging process with an initial forging temperature a bit above $\beta$ transformation and finishing the forging a little below the $\beta$ transformation is suggested to balance the forging deformation resistance and forged mechanical properties.

\section{Introduction}

Ti-6Al-4V is one of the most widely used titanium alloys in the aeroengine fields due to its high strength, relatively low density, excellent corrosion resistance, and good creep resistance [1-4]. As a dual-phase alloy consisting of alternate layers of hexagonal close packed (HCP) $\alpha$ and body-centered cubic (BCC) $\beta$ phases, its mechanical properties are very much dependent on the microstructure morphologies $[5,6]$. The Ti- $6 \mathrm{Al}-4 \mathrm{~V}$ alloy is commonly presented as as-cast ingots with $\beta$ transformed lamellar structure, and researches have shown that the microstructures of titanium alloys will change to isometric, dualstate, and lamellar structures during the dynamic plastic deformation (DPD) process, which will lead to the improvement of its mechanical properties [7-11]. So many thermomechanical processes, such as extrusion [12], forging [13, 14], and hot rolling [15], are carried out to modify its microstructures to the needed morphologies with equiaxed, lamellar, and bimodal.
In the past several years, many efforts have been made to understand the deformation mechanisms and the microstructure evolution of titanium alloys [16-18]. The DPD process at different strain rates were carried out to evaluated the strain rates effects on the microstructural refine and the strength improvement of the alloy $[19,20]$. The deformation temperature effects were also investigated to provide the optimized deformation parameters and evaluate the different deformation mechanism of the hot extrusion and rolling technology $[12,15]$. Further, the complex relationships between material properties and DPD process parameters have also been studied to improve the strength and plasticity of the titanium alloys [21-26].

Of most DPD studies, the DPD was carried out by press forging at low constant strain rates $\left(<10^{1} \cdot \mathrm{s}^{-1}\right)$ in thermal simulator with the static presses powered hydraulically and focused on the deformation temperatures and height reductions effects on the microstructure and mechanical properties of titanium alloys. However, a few researchers 
have mentioned that high strain rate combining with certain deformation can refine the grains better and obtain nanostructured metallic materials [19, 27]. However there are seldom studies concerning the high strain rate DPD process achieved by continuous multipass hammer forging in which the high strain rate could be imposed by the hammer blow.

Considering that the DPD achieved by multipass hammer forging with high impact velocities and forging frequency could efficiently reduction the forging time, it is assumed that the multipass hammer forging could be finished during a short term with a high strain rate, which will benefit the microstructure of the titanium alloy. So, this paper focuses on the DPD achieved by multipass hammer forging and studies the temperature effects on the multipass hammer forging process, the microstructure, and the mechanical properties of the forged Ti-6Al-4V alloy. It aims to understand the relationship between the microstructure, mechanical properties, and the multipass hammer forging parameters.

\section{Materials and Experimental Procedures}

2.1. Materials. Commercially available Ti-6Al-4V alloy bars were used in this study, and the chemical compositions of asreceived material are listed in Table 1 . The measured $\beta$ transition temperature of this material is about $990^{\circ} \mathrm{C}$. The as-received bars with a diameter of $355 \mathrm{~mm}$ and a length of $550 \mathrm{~mm}$ were produced by ingot metallurgy, and they were cutting to cuboid samples with the length, width, and height equal to $100 \mathrm{~mm}, 50 \mathrm{~mm}$, and $80 \mathrm{~mm}$, respectively, by wire electrical discharge machining (WEDM) along the diameter direction of the cylindrical ingot.

2.2. Multipass Hammer Forging Process. Considering that the ram of hammer forging machine can be accelerated by gravity and hydraulic fluid simultaneously and a short forging time and high forging frequency could be controlled, an open-die hammer forging machine [28] was used to carry out the multipass forging process.

The multipass forging process was divided into four steps for every sample, as shown in Figure 1. Firstly, the samples were placed in the preheated molds and then heated to the forging temperature in a special heating furnace with a heating rate of $6^{\circ} \mathrm{C} / \mathrm{min}$. In order to ensure the uniform temperature distribution inside and outside the samples, the samples were kept in the furnace under forging temperature for a period in the second step, and it was determined to $60 \mathrm{~min}$ due to the minimum width of samples. In the third step, the samples were stricken three passes in one direction, with a high-speed camera ( 5000 sheets/s) used to record the time of each strike. It is reported that the microstructure of alloys can be obviously refined with a more than $20 \%$ height reduction, and the crystallization rate will increase dramatically with a deformation over $12 \%$ in a single strike [29]. Therefore, a total forging deformation of $50 \%$ was controlled by the position limiter in the forging process. Finally, the forged samples were cooled to room temperature by air cooling (AC).

It is known that the titanium will crystallize to $\alpha$-phase with a HCP structure in low temperature and transforms to
TABle 1: Chemical composition of Ti-6Al-4V alloy used in this study.

\begin{tabular}{lcccccc}
\hline Elements & $\mathrm{Al}$ & $\mathrm{V}$ & $\mathrm{Fe}$ & $\mathrm{C}$ & Impurity & $\mathrm{Ti}$ \\
\hline (Wt.\%) & 6.4 & 4.1 & 0.17 & 0.02 & $\leq 0.30$ & $\mathrm{Bal}$ \\
\hline
\end{tabular}

$\beta$-phase with BCC structure in high temperature, as shown in Figure 2, thus the forging of titanium is divided into $\alpha+\beta$ forging and $\beta$ forging. During the $\alpha+\beta$ forging, the alloy should be heated to a temperature $30^{\circ} \mathrm{C}$ to $100^{\circ} \mathrm{C}$ below the $\beta$ transition temperature. While for $\beta$ forging, the alloy is first heated above the $\beta$ transition temperature, and the forging process should be finished before the $\beta$ to $\alpha$ transformation starts. In order to study the forging temperature effects on the forging process, the microstructural and the mechanical properties of forged samples and three different forging types with five different forging temperatures were selected based on the $\beta$ transition temperature $T_{\beta}$, as shown in Table 2 . The near $\beta$ forging type in Table 2 is defined to characterize the forging process with a temperature only a little below the $\beta$ transition temperature due to the low $\alpha$ volume phase fraction in the alloy under this temperature.

2.3. Mechanical Properties and Microstructure Test. Five groups tensile specimens with five specimens in each group were cut from each forged samples, and the tensile tests were performed on an MTS mechanical machine with the tensile speed of $10 \mathrm{~mm} / \mathrm{min}$ at room temperature, and the tensile strain rate is $6.67 \times 10^{-3} \mathrm{~s}^{-1}$. The averaged mechanical properties of each specimens were calculated after the tensile tests. The dimension of each specimen is shown in Figure 3(a).

Cube specimens with the dimension of $10 \times 10 \times 10 \mathrm{~mm}^{3}$ were obtained by wire cutting along the forging direction to observe the microstructure. Then, the microstructure of the specimens was observed using optical microscope (OM) after the process of grinding, polishing, and chemical etched in a solution of $13 \% \mathrm{HNO}_{3}, 7 \% \mathrm{HF}$, and $80 \% \mathrm{H}_{2} \mathrm{O}$ for $1 \mathrm{~min}$. The fracture morphology of tensile specimens was observed by scanning electron microscope (SEM).

\section{Results and Discussion}

3.1. Initial Microstructure before Multipass Hammer Forging. Figure 4 shows the initial microstructure of the Ti-6Al-4V bar before forging. The metallographic figures show that the primary $\beta$ phase as a small seam around the coarsely and lightly colored primary lamellae $\alpha$ phase.

\subsection{Microstructural Characterization after Multipass Ham-} mer Forging. The microstructure evolution after the multipass hammer forging process was investigated by detecting the microstructure of the five forged samples, and the microstructures are shown in Figure 5. At the temperature of $925^{\circ} \mathrm{C}$, after three-pass hammer forging, the morphology with equiaxed $\alpha$ phase, rod-like $\alpha$ phase, and olivary $\alpha$ phase lying in the lamellar $\alpha+\beta$ matrix could be seen in Figure 5(a), and these $\alpha$ phases have more smaller sizes contrary to the original coarse lamellae $\alpha$ phases. The multipass hammer process efficiently 


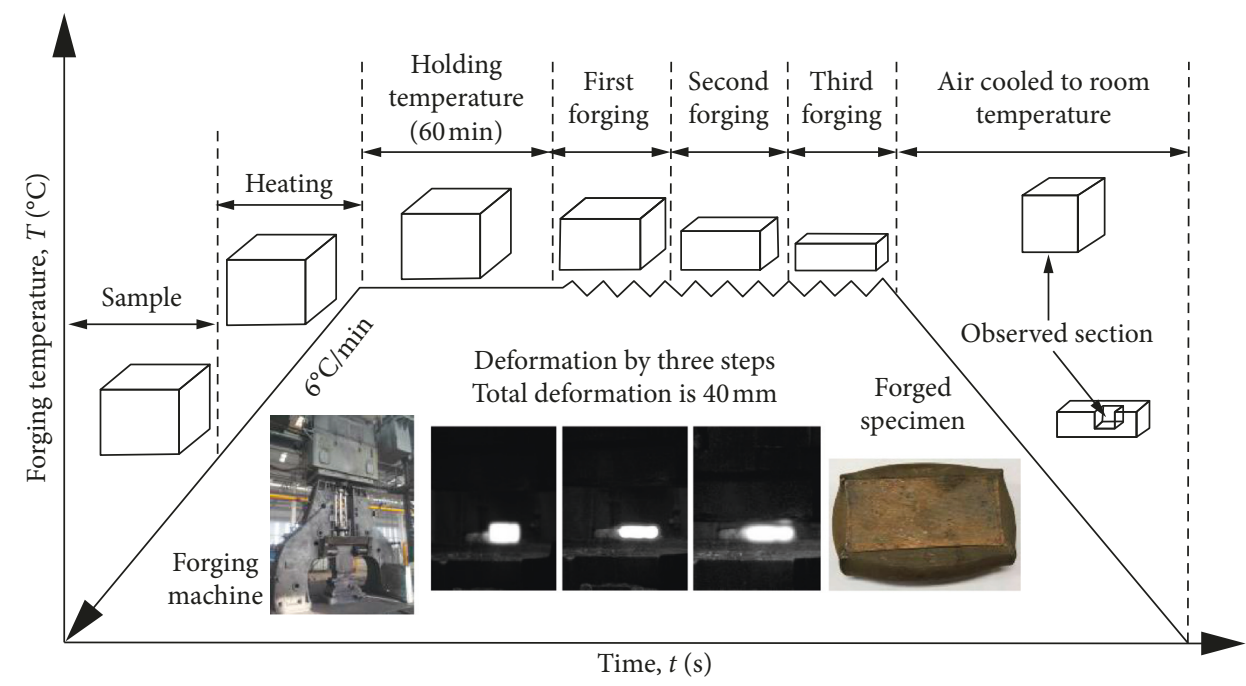

FIGURE 1: Detailed experimental design for description of forging experimental procedure.

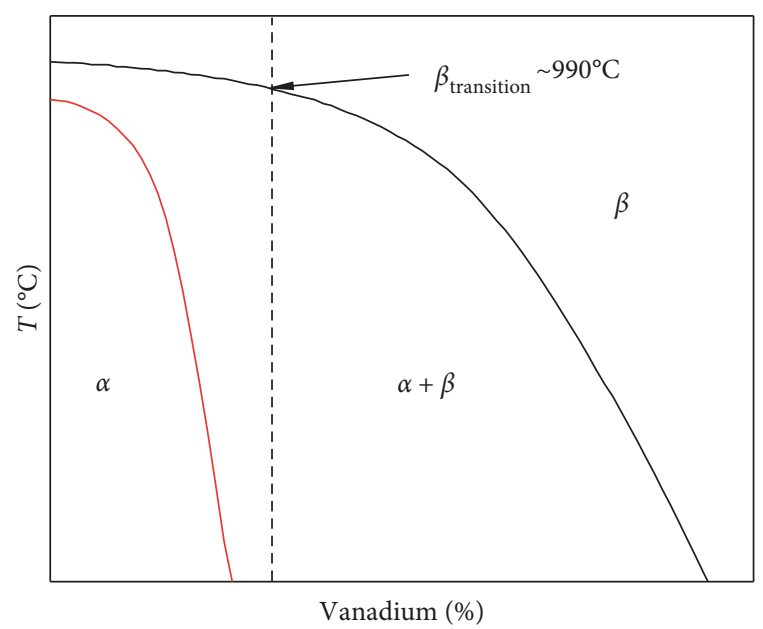

Figure 2: Pseudobinary phase diagram (schematic) of $\alpha-\beta$ titanium alloy.

TABLE 2: Selected forging temperatures and corresponding alloy phases.

\begin{tabular}{|c|c|c|c|c|}
\hline Sample no. & $\begin{array}{r}\text { Forg } \\
\text { temper } \\
T\left({ }^{\circ}\right.\end{array}$ & $\begin{array}{l}\text { ng } \\
\text { ture, } \\
\text { C) }\end{array}$ & Alloy phases & Forging types \\
\hline $1^{\#}$ & $T_{\beta}-65$ & 925 & $\alpha+\beta$ & $\alpha+\beta$ forging \\
\hline $2^{\#}$ & $T_{\beta}-40$ & 950 & $\alpha+\beta$ & $\alpha+\beta$ forging \\
\hline $3^{\#}$ & $T_{\beta}^{p}-15$ & 975 & $\beta+$ insignificant $\alpha$ & Near $\beta$ forging \\
\hline $4^{\#}$ & $T_{\beta}+10$ & 1000 & $\beta$ & $\beta$ forging \\
\hline $5^{\#}$ & $T_{\beta}+35$ & 1025 & $\beta$ & $\beta$ forging \\
\hline
\end{tabular}

broke down the coarse as-cast lamellar microstructure, and then the broken piece lamellae recrystallize to globular primary $\alpha$ phases. With the temperature increases to $950^{\circ} \mathrm{C}$ and $975^{\circ} \mathrm{C}$, similar globularization of the lamellar microstructure also took place, as shown in Figures 5(b) and 5(c). However, the morphology is slightly different. According to the thermodynamics theory of phase transformation, the total volume fraction of $\alpha$ phase is mainly associated with the forging temperature. Higher forging temperature will lead to lower volume fraction of $\alpha$ phase. When the forging temperature increases from $925^{\circ} \mathrm{C}$ to $950^{\circ} \mathrm{C}$ and $975^{\circ} \mathrm{C}$, the volume fraction of the primary $\alpha$ phase decreases due to the $\alpha+\beta \longrightarrow \beta$ transformation and more needlelike $\alpha+\beta$ lamellar matrix appear.

When the temperature increases above the $\beta$ transformation temperature to $1000^{\circ} \mathrm{C}$ or $1025^{\circ} \mathrm{C}$, all the phases change to $\beta$ phase and the forging corresponding to $\beta$ forging processes. Once the forged sample is cooled from temperatures above the $\beta$ transformation temperature, the $\alpha$ phase nucleates at grain boundaries and then grows as lamellae into the prior $\beta$ phase, and then the fine needlelike $\alpha+\beta$ lamellar phase is formed as shown in Figures 5(d) and 5(e). However, insignificant differences exist between the two figures. The forged sample morphology seems to have the equiaxed $\alpha$ phases scatter into the needlelike $\alpha+\beta$ matrix at $1000^{\circ} \mathrm{C}$ but all needlelike $\alpha+\beta$ lamellae at $1025^{\circ} \mathrm{C}$. The reason for this difference maybe that the forging temperature of $1000^{\circ} \mathrm{C}$ is just above the $\beta$ transformation, it decreases below the $\beta$ transformation temperature, and a near $\beta$ forging was actually carried out. By comparing Figures 5(c) and 5(d), the similar bimodal microstructures that consist partly of equiaxed primary $\alpha$ in a lamellar $\alpha+\beta$ matrix are found, and the more little equiaxed primary $\alpha$ in Figure 5(d) due to a higher temperature.

3.3. Strain Rate of the Forging Process. In the multipass hammer forging process, the strain rate of each strike was calculated by the sample deformation and deformation time in each strike:

$$
\dot{\varepsilon}=\frac{\Delta h}{h} \cdot \frac{1}{t}
$$

where $\dot{\varepsilon}$ is the forging strain rate, $\mathrm{s}^{-1} ; h$ is the initial height of the sample before each strike, $\mathrm{mm} ; \Delta h$ is the height reduction samples in the strike, $\mathrm{mm}$; and $t$ is the strike time, s. The measured forging parameters of each strike for the five different samples are listed in Table 3. 


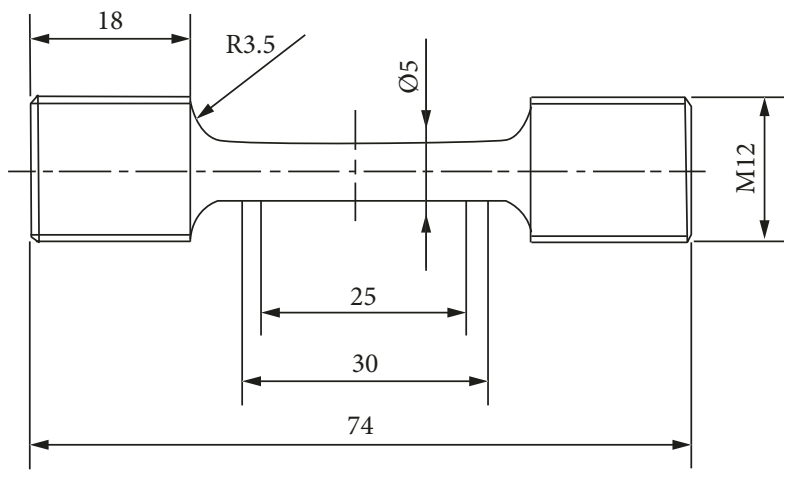

(a)

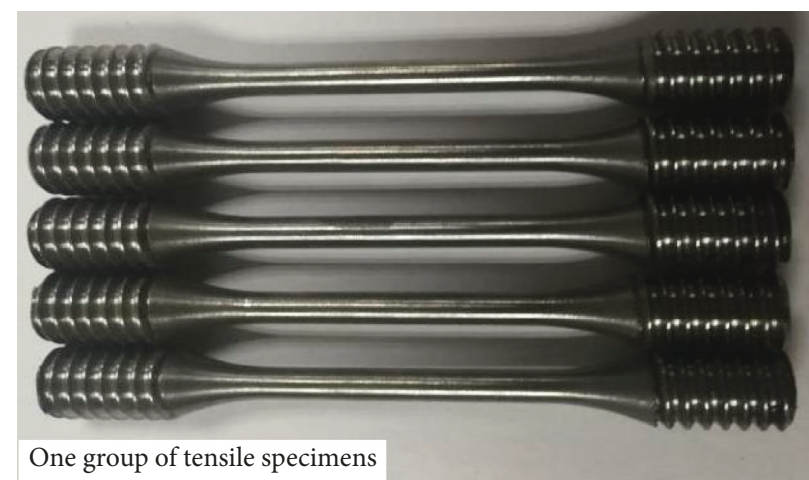

(b)

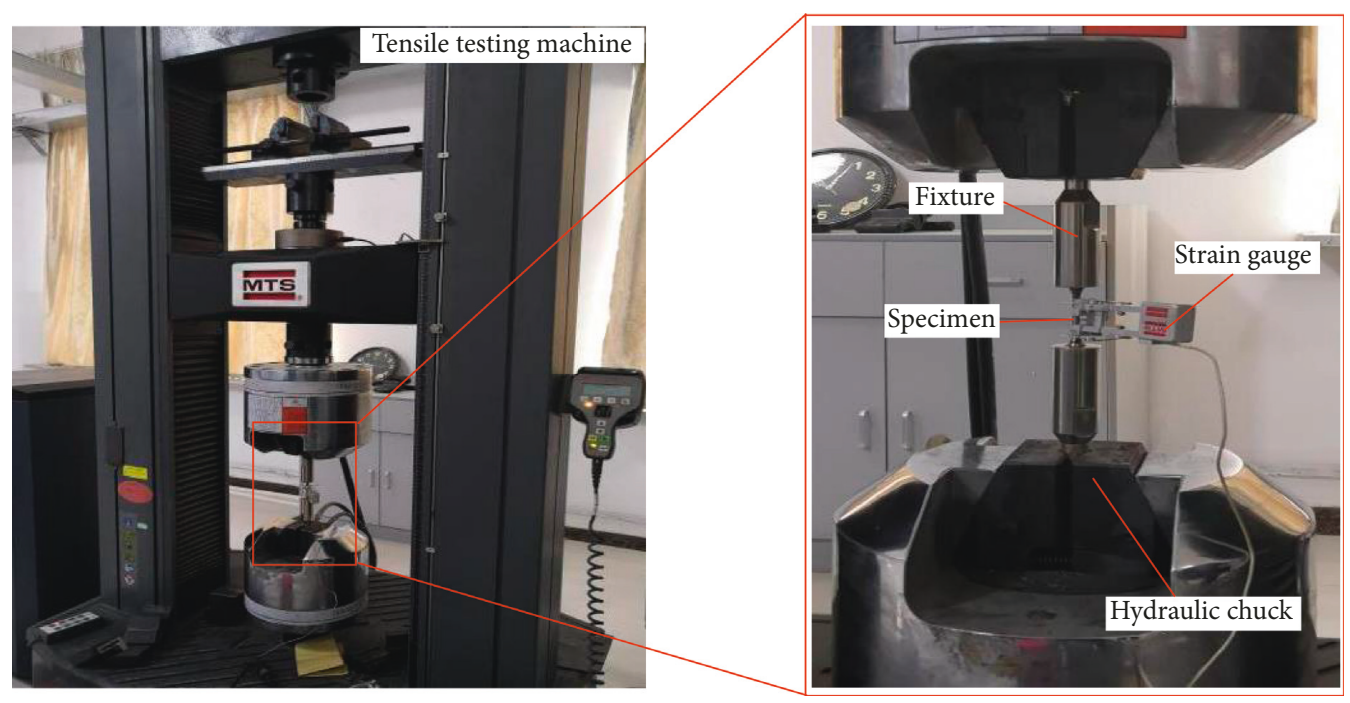

(c)

FIGURE 3: Schematic of mechanical properties test. (a) Dimensions of specimen; (b) one group of tensile specimens; (c) MTS tensile testing machine.

By substituting the parameters in Table 3 into equation (1), the strain rate of each strike could be achieved and is shown in Figure 6, which shows the variation of strain rate with temperature and forging processes. It can be seen that the strain rate of first strike increases with the forging temperature, which could be interpreted by the volume fraction increasing of $\beta$ phase due to the temperature increases. Generally, the plastic deformability is associated with the number of slip systems, which is determined by the number of slip planes multiplied by the number of slip directions. These planes and directions of highly dense packed atoms are energetically most favorable for plastic deformation. The denser slip planes are packed with atoms, the easier dislocations can glide. Therefore, a slip plane in the HCP lattice with a packing density of $91 \%$ should be superior to a slip plane in the BCC lattice with a packing density of only $83 \%$. The $\alpha$ phase of titanium has a HCP lattice while the $\beta$ phase has a BCC lattice, so the increased $\beta$ phase 


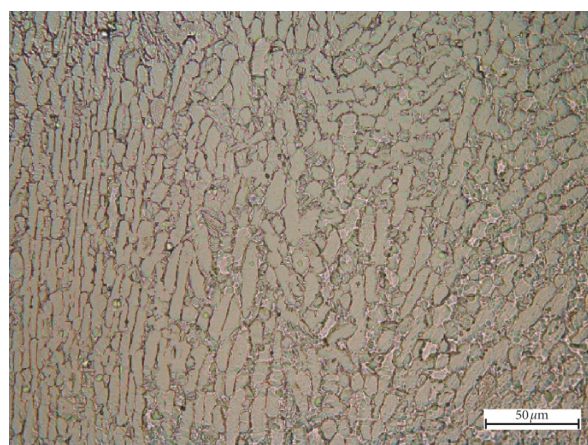

(a)

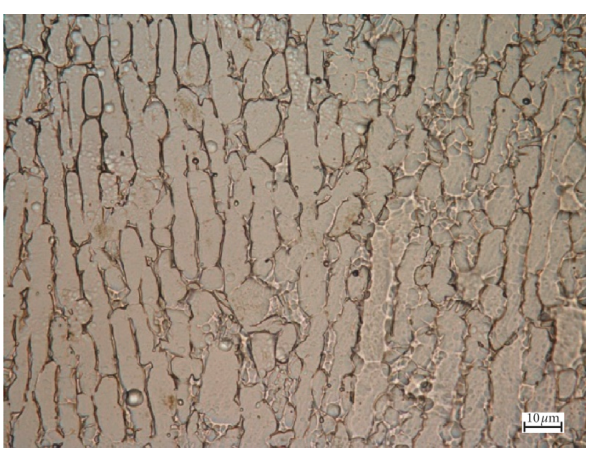

(b)

FIGURE 4: Microstructure of as-received Ti-6Al-4V alloy: (a) 50x and (b) 100x.

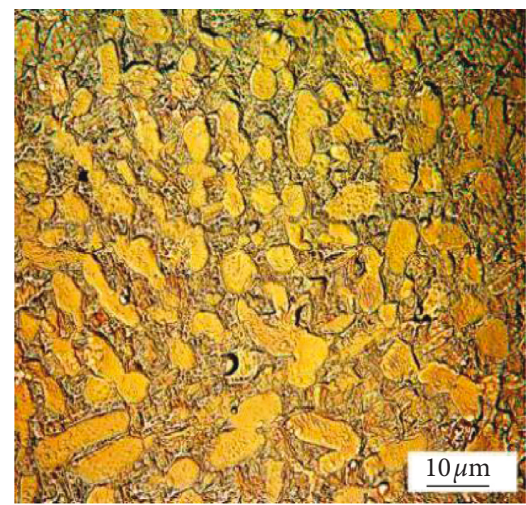

(a)

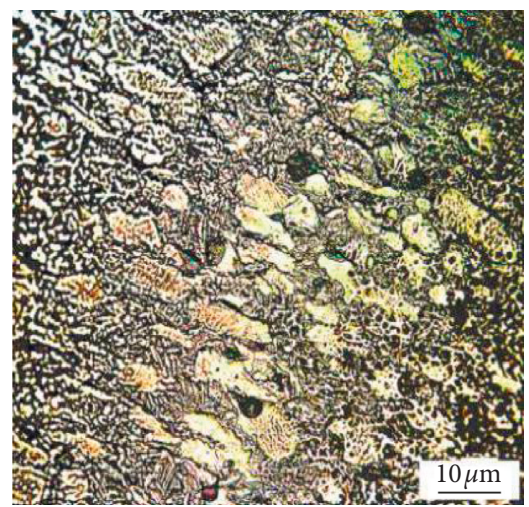

(c)

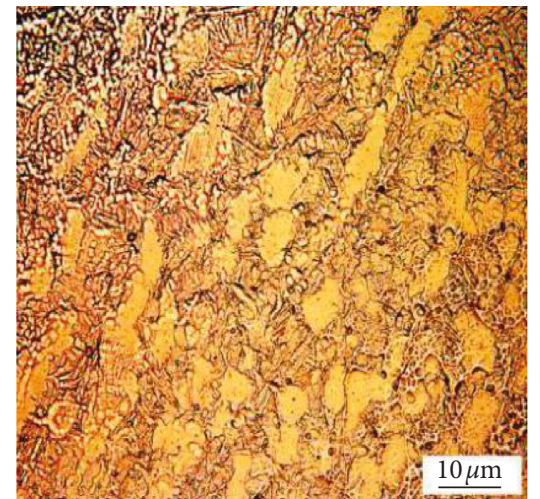

(b)

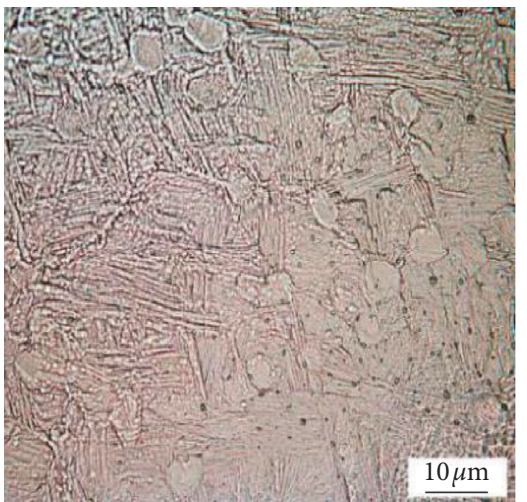

(d)

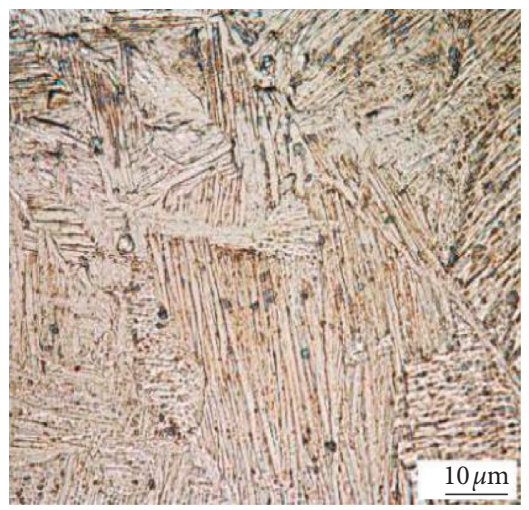

(e)

Figure 5: Typical metallographic images of samples prepared at different forging temperatures: (a) $925^{\circ} \mathrm{C}$; (b) $950^{\circ} \mathrm{C}$; (c) $975^{\circ} \mathrm{C}$; (d) $1000^{\circ} \mathrm{C}$; (e) $1025^{\circ} \mathrm{C}$. 
TABle 3: Parameters related to the multipass hammer forging.

\begin{tabular}{lcccccccc}
\hline \multirow{2}{*}{ Sample no. Forging temperature, $T\left({ }^{\circ} \mathrm{C}\right)$} & \multicolumn{2}{c}{ First step strike } & \multicolumn{2}{c}{ Second step strike } & \multicolumn{2}{c}{ Third step strike } & Total deformation reduction \\
& & $\Delta h(\mathrm{~mm})$ & $T\left(10^{-3} \mathrm{~s}\right)$ & $\Delta h(\mathrm{~mm})$ & $t\left(10^{-3} \mathrm{~s}\right)$ & $\Delta h(\mathrm{~mm})$ & $t\left(10^{-3} \mathrm{~s}\right)$ & $(\%)$ \\
\hline 1 & 925 & 10 & 12.3 & 14 & 19.3 & 16 & 24.0 & 50 \\
2 & 950 & 10 & 11.6 & 12 & 14.9 & 18 & 24.1 & 50 \\
3 & 975 & 14 & 16.0 & 12 & 14.6 & 14 & 17.8 & 50 \\
4 & 1000 & 18 & 19.4 & 12 & 13.9 & 10 & 11.0 & 50 \\
5 & 1025 & 16 & 16.0 & 14 & 15.3 & 10 & 12.0 & 50 \\
\hline
\end{tabular}

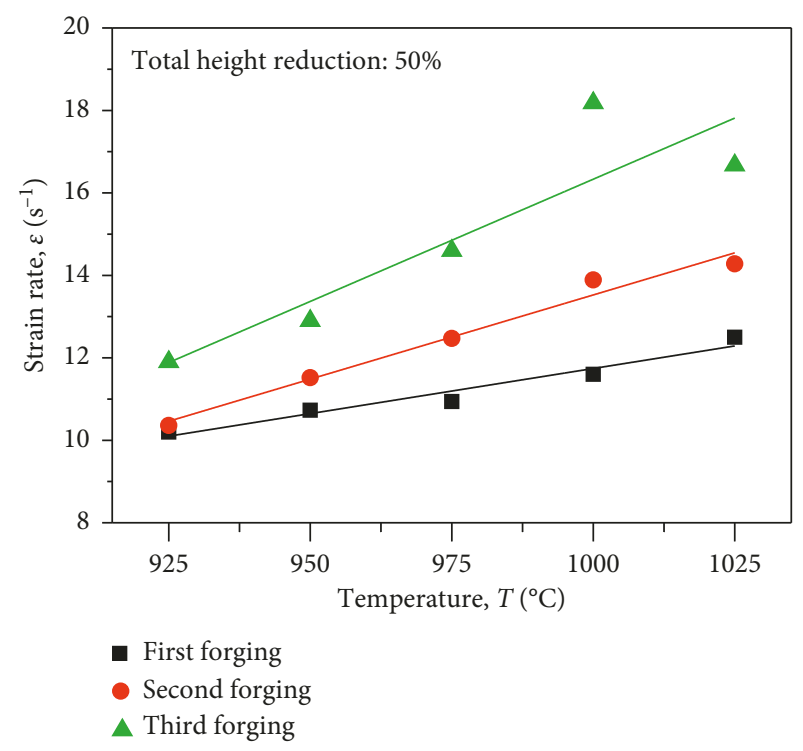

FIGURE 6: Strain rate-temperature curves for multiple forging times.

volume fraction caused by increased temperature increases the slip possibility of the alloy and lead to a larger strain rate. With the increase of temperature, the internal energy of the alloy also increases, and this could decrease the energy needed for atom movement and also lead to the decrease of deformation resistance and the improvement of mobility.

As shown in Figure 6, at temperature of $925^{\circ} \mathrm{C}$, the strain rate of the first strike is $10 \mathrm{~s}^{-1}$ and increases insignificantly in the second strike, but it increases to about $12 \mathrm{~s}^{-1}$ in the third strike. The strain rate increases with the multipass strikes going on seems to occur in all evaluated forging temperature, which means a better mobility and plasticity of the material could be achieved by multipass strike than only one pass strike. Tang et al. [30] examined the microstructure and texture evolution during the multipass forging process, and they found that the volume fractions of $\alpha$ phase are $77.37 \%$, $84.38 \%, 83.83 \%$, and $78.20 \%$, respectively, from the first pass forging to the forth pass forging; there are only insignificant changes of $\alpha$ phase due to the small temperature difference between the different passes. Thus, the strain rate improvement is not caused by the increase of $\beta$ phase. With the going on of the following forging pass, the volume fraction and grain size of primary $\alpha$ phase $\alpha_{\mathrm{p}}$ increase. The size range of $\alpha_{\mathrm{p}}$ changes from $9.88-37.21 \mu \mathrm{m}$ after the first pass forging to $4.93-25.7 \mu \mathrm{m}, 5.56-31.35 \mu \mathrm{m}$, and $7.78-40.96 \mu \mathrm{m}$ after the following three pass forging. Meanwhile, the volume fraction of $\alpha_{\mathrm{p}}$ raises from $30.15 \%$ to $36.07 \%, 39.22 \%$, and $43.70 \%$ during the multipass forging process. Jha et al. [31] claimed that the lamellar morphology of microstructure resists the deformation initially to a greater extent compared to equiaxed morphology and causes higher flow stress compared to equiaxed. On further deformation, the lamellar microstructure kinks, bends, and breaks resulting in higher flow softening than equiaxed morphology. Thus, the increased size and volume fraction of primary $\alpha$ phase may associate with the strain rate increase for multipass hammer forging at evaluated temperature. The increase of strain rates for the second and third strikes with increasing temperature are also demonstrated in Figure 5, and this could also attributed to the volume fraction improvement of $\beta$ phase and the decrease of active energy needed for atom movement.

To evaluate the forging effects on the strain rate, a strain rate ratio is defined as

$$
\chi=\frac{\dot{\varepsilon}_{i+1}}{\dot{\varepsilon}_{i}},
$$

where $\chi$ is strain rate ratio, which denotes the forging effects on the strain rate; $\dot{\varepsilon}_{i+1}$ and $\dot{\varepsilon}_{i}(i=1,2)$ are strain rates of the $i+1$ and $i$ pass strike, respectively, at evaluated temperature.

As shown in Figure 7, in the temperature of $925^{\circ} \mathrm{C}$ to $1000^{\circ} \mathrm{C}$, the $\dot{\varepsilon}_{2} / \dot{\varepsilon}_{1}$ increases linearly from about 1.03 to 1.2 with forging temperature, which indicates that the slip possibility of the alloy has been improved by the first strike. The slip possibility of the alloy improved only $3 \%$ at $925^{\circ}$; the effect is not significant, but a $20 \%$ mobility improvement could be achieved at $1000^{\circ} \mathrm{C}$. When comparing the strain rates of the third strike and the second strike by $\dot{\varepsilon}_{3} / \dot{\varepsilon}_{2}$, a dramatic improvement of strain rate about $15 \%$ was achieved at $925^{\circ} \mathrm{C}$ after the second strike; the strike effect is much higher than the first strike, the reason maybe that at a relative lower temperature, the microstructure is coarse lamellae, which has a larger broken resistant, so the first strike only breaks the lamellae to coarse segments, and leads to a slow recrystallization and globularization of lamellar structure. But, the second strike efficiently broke the coarse lamellae to small pieces and accelerated the recrystallization and globularization process, which leads to the dramatic improvement of the mobility. The alloy mobility improved by the second strike at $950^{\circ} \mathrm{C}$ and $975^{\circ} \mathrm{C}$ is also obvious with $11.3 \%$ and $11.7 \%$, even though the second strike is more meaningful for lower temperature, as after the first and second strikes, the strain rate improvement is $3 \%$ and $15 \%$ at $925^{\circ} \mathrm{C}$, while the values are $11.4 \%$ and $11.7 \%$ at $975^{\circ} \mathrm{C}$, and the marginal efficiency of the second strike decreases with the increase of temperature. However, a multipass strike at high temperature still has their meaning of existence as a multipass hammer could refine the 


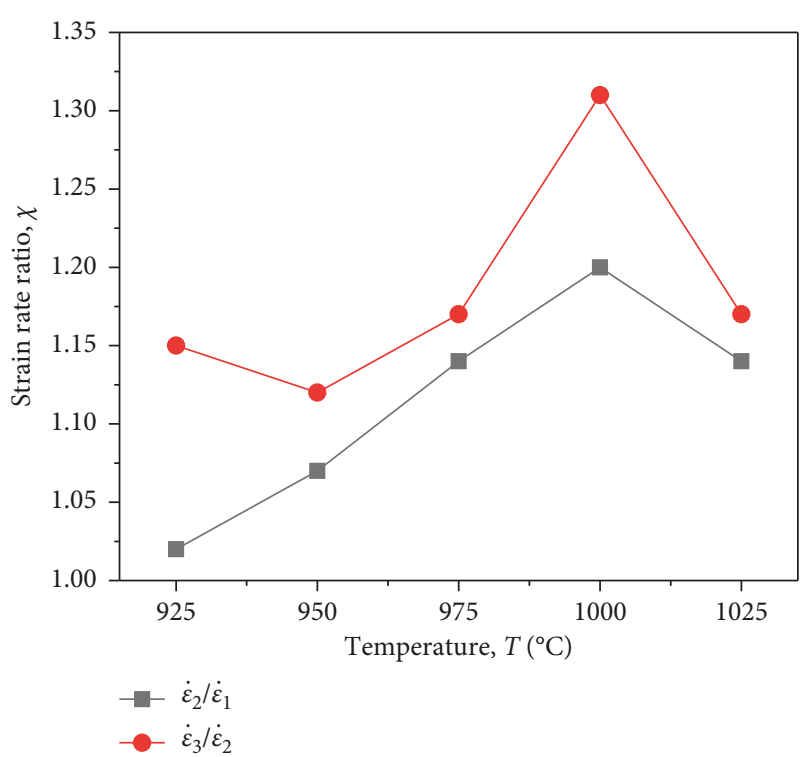

FIGURE 7: Strain rate sensitivity coefficient for forging temperature and forging number.

microstructure and improve the recrystallization and globularization of lamellar structure to $\alpha_{\mathrm{p}}$, which is a benefit for improving the material properties.

\subsection{Effects of Multipass Hammer Forging on Mechanical Properties}

3.4.1. Material Properties of Forged Sample at Different Temperatures. The stress-strain curves and the mechanical properties such as yield stress (YS), ultimate tensile strength (UTS), elongation (EL), and reduction of fracture area of the forged samples at different temperatures are shown in Figure 8. As demonstrated in Figure 8(a), with the increase of forging temperature, the fracture strain decreases from 0.217 to 0.137 and the fracture stress increases. At the temperature below $\beta$ transformation, the YS decreases from $1026 \mathrm{MPa}$ to $1008 \mathrm{MPa}$ with the increase of forging temperature, accompanied with the UTS decrease from $1086 \mathrm{MPa}$ to $1070 \mathrm{MPa}$. When the forging temperature increases to only a little above the $\beta$ transformation, both the YS and the UTS have a high value of $1014 \mathrm{MPa}$ and $1086 \mathrm{MPa}$, respectively, which almost reach the values at temperature of $925^{\circ} \mathrm{C}$. If the forging temperature increases continuously, both the YS and UTS decrease dramatically to a low level. The elongations of different specimens have an approximate negative linear relationship with temperature until it reaches the temperature a bit above the $\beta$ transformation and an insignificant decrease from $16.5 \%$ to $13.5 \%$. The elongation will decrease sharply to about $9.5 \%$ when the forging temperature further increases. The reduction of fracture area represents only a slight decrease from $46 \%$ to $43 \%$ when the forging temperature changes from $925^{\circ} \mathrm{C}$ to $950^{\circ} \mathrm{C}$, remains almost constant to the temperature a bit above the $\beta$ transformation, and then decreases significantly to $11 \%$.

The strength differences of the samples at different temperatures are mainly caused by the microstructures. The microstructure of titanium alloys is primarily determined by the size and arrangement of the $\alpha$ and $\beta$ phases, and the two extreme cases of phase arrangements are the lamellar microstructure, which is generated upon cooling from the $\beta$ phase field, and the equiaxed microstructure, which is a result of a recrystallization process. Numerous investigations have been subjected to how the size of the phases and the arrangement of the phases affect the mechanical properties. With the increase in volume fraction of equiaxed $\alpha$ phase, the strength of the alloy will increase. As the microstructure of forged samples shown in Figure 5 depicts, the primary equiaxed $\alpha$ phase decreases with the increasing forging temperature below the $\beta$ transformation temperature, which lead to the decrease of YS and UTS. The sample forged at $1025^{\circ} \mathrm{C}$ has the lowest YS and UTS, and the microstructure of this sample is all needlelike $\alpha+\beta$ lamellae, which will lead to the poor performance of strength. A special difference that should be pointed is that when forging temperature is only a little above the $\beta$ transformation, the sample also shows good strength performance, which is almost the same with the sample forged at $925^{\circ} \mathrm{C}$; this could be attributed to the achieved bimodal microstructure.

Similar to the strength, the ductility of the Ti-6Al-4V alloy also has a positive correlation with equiaxed $\alpha$ phase and a negative correlation with $\alpha+\beta$ lamellar microstructure. With an equiaxed $\alpha$ phase of finer grains, the strain inside and near the grain boundary of the finer grains varies insignificantly and the deformation is more uniform, so the chance of cracking due to stress concentration is much less and a larger amount of deformation could be sustained before fracture [32]. Therefore, the samples $1^{\#} \sim 4^{\#}$, which contain the equiaxed $\alpha$ phase, demonstrate larger elongation and reduction of fracture area than sample $5^{\#}$. The insignificant decrease of ductility may associate to the reduction of equiaxed $\alpha$ phase.

It is summarized according to Figure 8 that the forging temperature has a great influence on the YS and UTS. If the forging is carried out above the $\beta$ transformation temperature, a lamellar microstructure with low strength will be formed, while forging below the $\beta$ transformation temperature can achieve high YS and UTS. And, the lower the forging temperature, the higher strength achieved. However, the forging temperature should be in the range of $\alpha+\beta$ two-phase zone and ensures that the crack-free forging is possible at high degrees of deformation. Semiatin et al. [33] reported that the billets should be hot deformed below the $\beta$ transformation temperature to get a microstructure consisting of fine equiaxed primary $\alpha$ phase and transformed $\beta$. Brun et al. [34] also noted that the development of a regulated structure in $\alpha+\beta$ twophase titanium alloy was significant for the production of titanium alloy semiproducts. Although good strength could be achieved by forging under the $\beta$ transformation temperature, the mobility of the metal is not good at low temperature. As the flow curves demonstrate in Figure 9 [35], the yield stress at the temperature above $\beta$ transformation is very low and almost present as a constant, when the temperature drops to below the $\beta$ transformation temperature, and the deformation resistance increases with the decreased temperature. So, a balance should be concerned to ensure the good mobility during the forging 


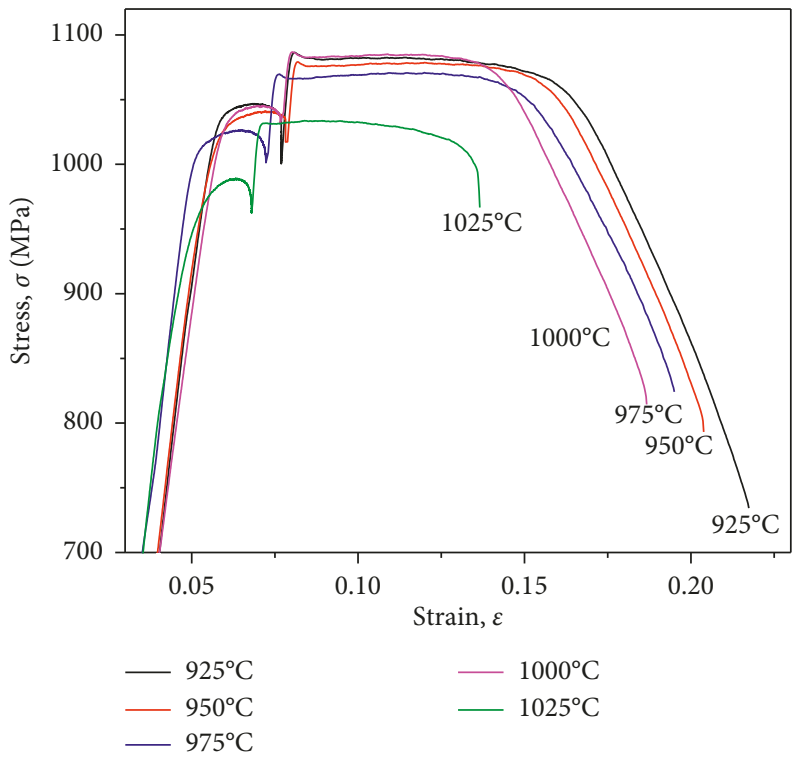

(a)

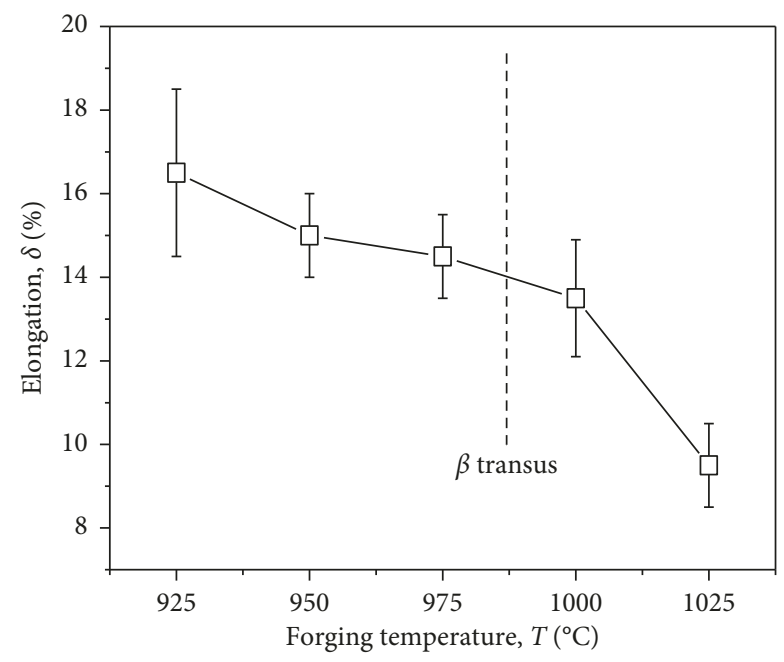

(c)

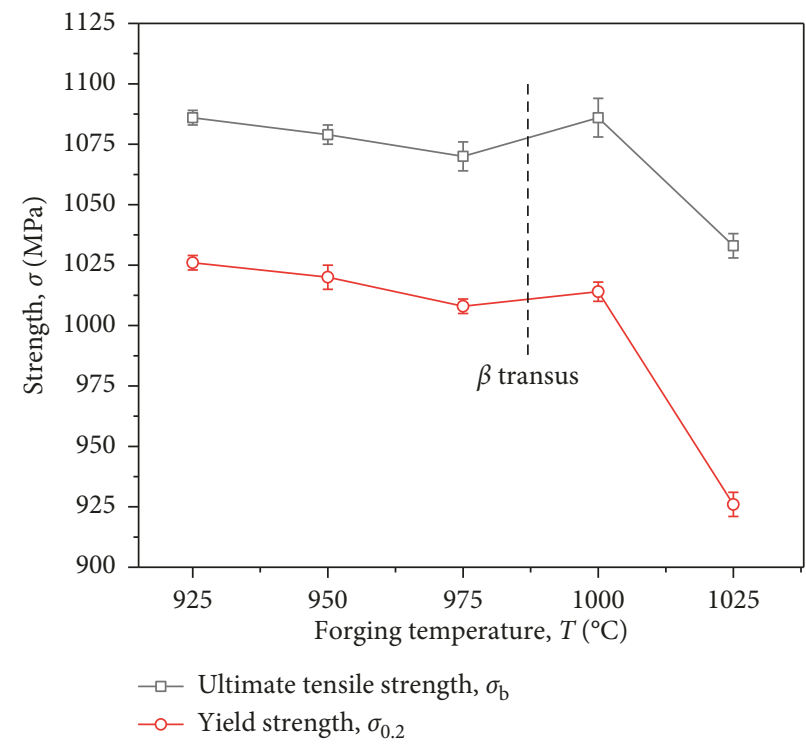

(b)

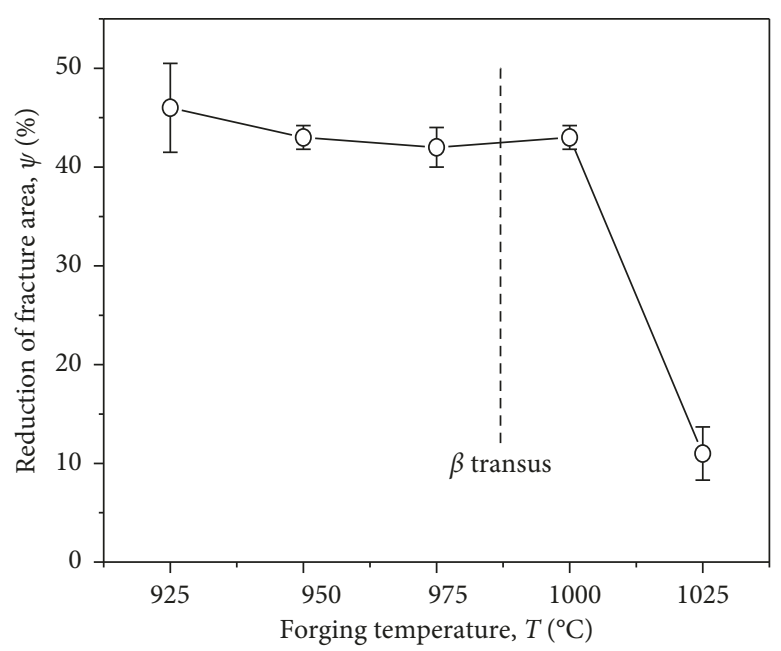

(d)

FIGURE 8: The stress-strain curves and the mechanical properties of the samples forged at different temperatures. (a) Stress-strain curves; (b) yield strength and ultimate tensile stress; (c) elongation and (d) reduction of area.

process and good mechanical properties after the forging when designing the forging process.

By considering the five forged samples, it is found that the sample forged at the temperature only a little above the $\beta$ transformation has the maximum strain rate compared to the sample forged at the temperature below the $\beta$ transformation. Even the sample $4^{\#}$ is forged above the $\beta$ transformation temperature, its YS and UTS are almost the same with sample $1^{\#}$, which is the $\alpha+\beta$ forging, and the reduction of ductility is insignificant. The microstructure of sample $4^{\#}$ is bimodal, which is formed under $\beta$ transformation temperature, thus the sample $4^{\#}$ was initially heated to the temperature above $\beta$ transformation to reduce the deformation resistance; the forging was finished at the temperature a little below the $\beta$ transformation to achieve a bimodal microstructure, and this process can achieve the balance. So it is suggested that during the multipass hammer forging process, the first step is isothermal forging conducted in the $\beta$ phase zone, and the following forging should be finished at the temperature a little below the $\beta$ transformation.

The mechanical properties of samples with multipass hammer forging are compared in Table 4 with the press forging results reported in the literatures $[36,37]$; it can be seen that the YS and UTS are all improved by multipass hammer forging; the elongation and the reduction of fracture area have little differences. Thus, it could be concluded that the mechanical properties of the Ti-6Al-4V alloy obtained by multipass hammer forging is better than that of press forging.

3.4.2. Fracture Morphology Observation. The tensile fracture morphology of different specimens was observed by scanning electron microscope (SEM), and the results are shown in Figure 10. Figure $10(\mathrm{a})$ is the fracture morphology at temperature of $925^{\circ} \mathrm{C}$; an obvious fiber region was found in 


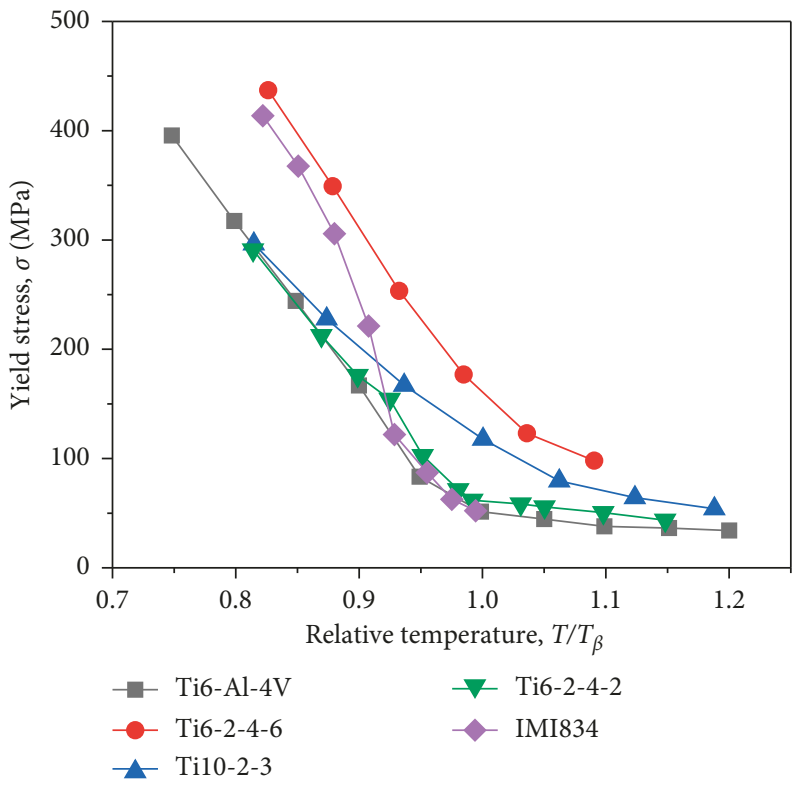

Figure 9: Flow curves of titanium alloys [35].

TABLE 4: Comparison of the mechanical properties of different forging processes.

\begin{tabular}{lcccc}
\hline Forging methods & Yield strength, $\sigma_{0.2}(\mathrm{MPa})$ & Ultimate tensile strength, $\sigma_{\mathrm{b}}(\mathrm{MPa})$ & Elongation, $\delta(\%)$ & Reduction of fracture area, $\Psi(\%)$ \\
\hline Press forging [36] & 925 & 960 & 15.5 & 44 \\
Press forging [37] & 1015 & 940 & 12.5 & 39 \\
Hammer forging & 1020 & 1079 & 15.0 & 43 \\
\hline
\end{tabular}

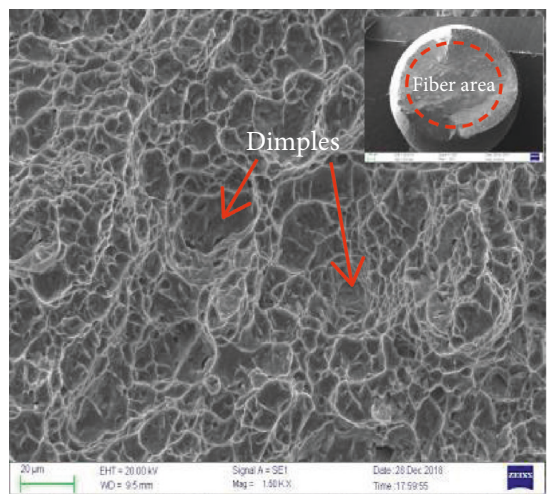

(a)

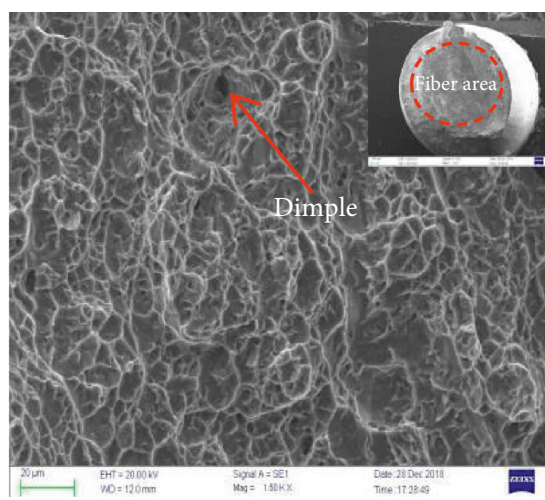

(c)

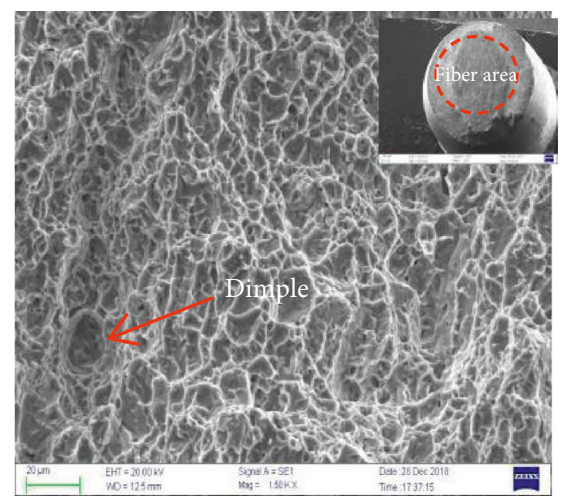

(b)

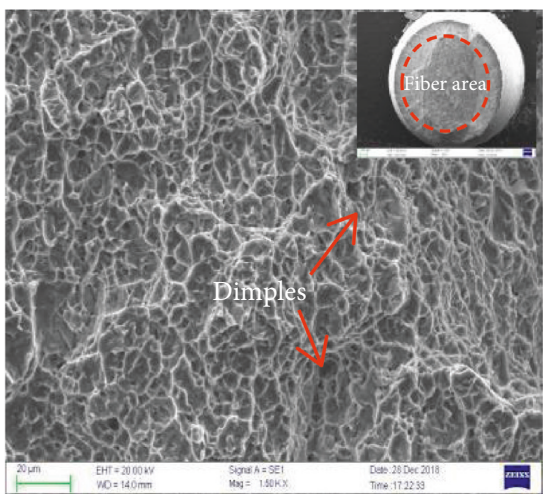

(d)

Figure 10: Continued. 


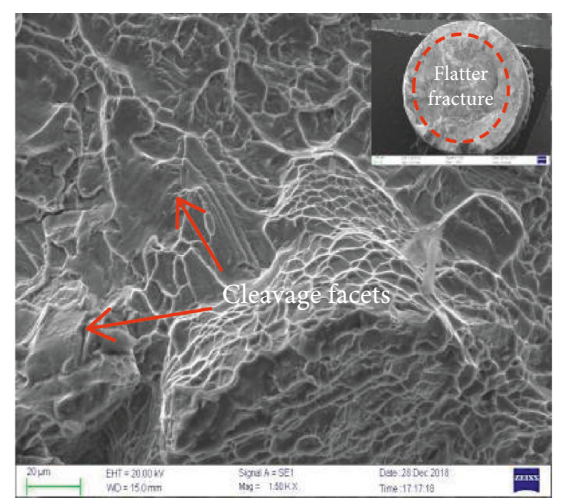

(e)

Figure 10: Fracture morphology at different forging temperatures: (a) $925^{\circ} \mathrm{C}$; (b) $950^{\circ} \mathrm{C}$; (c) $975^{\circ} \mathrm{C}$ (d) $1000^{\circ} \mathrm{C}$; (e) $1025^{\circ} \mathrm{C}$.

fracture surface, accompanied with a large number of spherical dimples with a dimension of $20 \mu \mathrm{m}$. A typical shear lip region and fibrous region, almost fully covered by deeper dimples with size of $10 \mu \mathrm{m}$, can be clearly observed in Figure 10(b). Meanwhile, it can be observed that deeper and small number of dimples with size of $5 \mu \mathrm{m}$ appeared on the fracture surface. From Figure 10(c), it is concluded that the fracture surface is a typical ductile fracture. Figure 10(d) shows the obvious fibrous region, and a large number of shallow depth dimples with $3 \mu \mathrm{m}$ were observed in fracture surface. Figure 10(e) shows the flatter and cleavage facets, and the intergranular fracture and cleavage fracture features finally lead to the worse plasticity at $1025^{\circ} \mathrm{C}$. At $925^{\circ} \mathrm{C}$, the spherical dimple size of the fracture surface of the tensile specimen of Ti-6Al-4V alloy is the largest, and there is no cleavage plane; the above analysis shows that the more the number of dimples and the larger the size, the better the plasticity properties of the material.

\section{Conclusions}

The effects of forging temperature on microstructure and mechanical properties of the multipass hammer forging process of Ti-6Al-4V alloy were investigated based on the integrated approaches of OM and SEM. The strain rate of each strike in the multipass hammer forging process was acquired and discussed. The main results can be summarized as follows:

(1) The coarse $\alpha+\beta$ lamellar microstructure was globularized and refined to a homogeneous equiaxed primary $\alpha$ phase located in the needlelike $\alpha+\beta$ lamellar phase after the three-pass hammer isothermal forging process.

(2) The YS and UTS of forged sample decrease with the increased temperature below the $\beta$ transformation, while the elongation and reduction of fracture area change insignificantly.

(3) The strain rate in a multipass hammer forging process increases with forging temperature and strikes; the alloy mobility could be improved by multipass strikes, but the marginal efficiency of the second strike decreases with the increased forging temperature.

(4) By heating the alloy to an initial temperature a bit above the $\beta$ transformation, the forging could be carried out with a low deformation resistance; by finishing the forging process below the $\beta$ transformation temperature slightly, a bimodal microstructure could be achieved. The forged sample exhibits high YS and UTS similar to a lower temperature forging in $\alpha+\beta$ zone and an insignificant loss of ductility. The designed forging process is suggested due to the balance of deformation stress and mechanical properties.

\section{Data Availability}

The data used to support the findings of this study are included within the article.

\section{Conflicts of Interest}

The authors declare that they have no conflicts of interest.

\section{Acknowledgments}

The authors gratefully acknowledge the financial support of this study by the National Natural Science Foundation of China (Grant no. 51775427) and the research fund of the State Key Laboratory for Marine Corrosion and Protection of Luoyang Ship Material Research Institute (LSMRI) under the contract no. 61429010102 .

\section{References}

[1] S. Roy and S. Suwas, "Unique texture transition during sub $\beta$-transus annealing of warm-rolled Ti-6Al-4V alloy: role of orientation dependent spheroidization," Scripta Materialia, vol. 154, pp. 1-7, 2018.

[2] N. Kherrouba, M. Bouabdallah, R. Badji, D. Carron, and M. Amir, "Beta to alpha transformation kinetics and microstructure of Ti-6Al-4V alloy during continuous cooling," Materials Chemistry and Physics, vol. 181, pp. 462-469, 2016. 
[3] Y. X. Liu, W. Chen, Z. Q. Li, B. Tang, X. Q. Han, and G. Yao, "The HCF behavior and life variability of a Ti-6Al-4V alloy with transverse texture," International Journal of Fatigue, vol. 97, pp. 79-87, 2017.

[4] G. G. Yapici, I. Karaman, and Z.-P. Luo, "Mechanical twinning and texture evolution in severely deformed Ti-6Al$4 \mathrm{~V}$ at high temperatures," Acta Materialia, vol. 54, no. 14, pp. 3755-3771, 2006.

[5] H.-Q. Chen and C.-X. Cao, "Characterization of hot deformation microstructures of alpha-beta titanium alloy with equiaxed structure," Transactions of Nonferrous Metals Society of China, vol. 22, no. 3, pp. 503-509, 2012.

[6] A. Sola, D. Bellucci, and V. Cannillo, "Functionally graded materials for orthopedic applications-an update on design and manufacturing," Biotechnology Advances, vol. 34, no. 5, pp. 504-531, 2016.

[7] H. J. Liu, L. Zhou, and Q. W. Liu, "Microstructural characteristics and mechanical properties of friction stir welded joints of Ti-6Al-4V titanium alloy," Materials \& Design, vol. 31, no. 3, pp. 1650-1655, 2010.

[8] B. Surowska, J. Bienias, M. Walczak, K. Sangwal, and A. Stoch, "Microstructure and mechanical properties of ceramic coatings on Ti and Ti-based alloy," Applied Surface Science, vol. 238 , no. 1-4, pp. 288-294, 2004.

[9] C. S. Meredith and A. S. Khan, "The microstructural evolution and thermo-mechanical behavior of UFG Ti processed via equal channel angular pressing," Journal of Materials Processing Technology, vol. 219, pp. 257-270, 2015.

[10] F. Jie, D. Hua, H. Yi, W. Zhang, and T. G. Langdon, "Influence of phase volume fraction on the grain refining of a Ti-6Al-4V alloy by high-pressure torsion," Journal of Materials Research and Technology, vol. 4, no. 1, pp. 2-7, 2015.

[11] J. Jayakumar, B. K. Raghunath, and T. H. Rao, "Enhancing microstructure and mechanical properties of AZ31-MWCNT nanocomposites through mechanical alloying," Advances in Materials Science and Engineering, vol. 2013, Article ID 539027, 6 pages, 2013.

[12] T. Seshacharyulu, S. C. Medeiros, W. G. Frazier, and Y. V. R. K. Prasad, "Microstructural mechanisms during hot working of commercial grade Ti-6Al-4V with lamellar starting structure," Materials Science and Engineering A, vol. 325, no. 1-2, pp. 112-125, 2002.

[13] I. Weiss, F. H. Froes, D. Eylon, and G. E. Welsch, "Modification of alpha morphology in Ti-6Al-4V by thermomechanical processing," Metallurgical Transactions A, vol. 17, no. 11, pp. 1935-1947, 1986.

[14] S. L. Semiatin, R. L. Goetz, V. Seetharaman, E. B. Shell, and A. K. Ghosh, "Cavitation and failure during hot forging of Ti6Al-4V," Metallurgical and Materials Transactions A, vol. 30, no. 5, pp. 1411-1424, 1999.

[15] J. L. W. Warwick, N. G. Jones, I. Bantounas, M. Preuss, and D. Dye, "In situ observation of texture and microstructure evolution during rolling and globularization of Ti-6Al-4V," Acta Materialia, vol. 61, no. 5, pp. 1603-1615, 2013.

[16] D. A. S. Macdougall and J. Harding, "A constitutive relation and failure criterion for Ti- $6 \mathrm{Al}-4 \mathrm{~V}$ alloy at impact rates of strain," Journal of the Mechanics and Physics of Solids, vol. 47, no. 5, pp. 1157-1185, 1999.

[17] S. M. Abbasi and A. Momeni, "Effect of hot working and postdeformation heat treatment on microstructure and tensile properties of Ti-6Al-4V alloy," Transactions of Nonferrous Metals Society of China, vol. 21, no. 8, pp. 1728-1734, 2011.

[18] S. Roy and S. Suwas, "The influence of temperature and strain rate on the deformation response and microstructural evolution during hot compression of a titanium alloy Ti-6Al4V-0.1B," Journal of Alloys and Compounds, vol. 548, no. 4, pp. 110-125, 2013.

[19] T. Naizhen and K. Lu, "Preparation technology of plastic deformation of nanostructured metal materials," Journal of Metals, vol. 50, no. 2, pp. 141-147, 2014.

[20] K. P. Rao and Y. V. R. K. Prasad, "Advanced techniques to evaluate hot workability of materials," Comprehensive Materials Processing, vol. 3, pp. 397-426, 2014.

[21] J. Luo, S. F. Liu, and M. Q. Li, "Quantitative analysis of microstructure and deformation mechanisms during isothermal compression of Ti-5Al-5Mo-5V-1Cr-1Fe alloy," Materials Characterization, vol. 108, pp. 115-123, 2015.

[22] J. Luo, M. Li, W. Yu, and H. Li, "The variation of strain rate sensitivity exponent and strain hardening exponent in isothermal compression of Ti-6Al-4V alloy," Materials \& Design, vol. 31, no. 2, pp. 741-748, 2010.

[23] K. Wang and M.-Q. Li, "Characterization of discontinuous yielding phenomenon in isothermal compression of TC8 titanium alloy," Transactions of Nonferrous Metals Society of China, vol. 26, no. 6, pp. 1583-1588, 2016.

[24] T. Seshacharyulu, S. C. Medeiros, W. G. Frazier, and Y. V. R. K. Prasad, "Hot working of commercial Ti-6Al-4V with an equiaxed $\alpha-\beta$ microstructure: materials modeling considerations," Materials Science and Engineering: A, vol. 284, no. 1-2, pp. 184-194, 2000.

[25] B. Zhao, Y. Zhao, Z. Hou et al., "Design and optimization of the processing parameters of Ti-5Al-3V-3Zr-0.7Cr titanium alloy as a candidate material for pressure hull of fusion reactor," Fusion Engineering and Design, vol. 137, pp. 405-413, 2018.

[26] J. Luo and M. Q. Li, "Strain rate sensitivity and strain hardening exponent during the isothermal compression of Ti60 alloy," Materials Science and Engineering: A, vol. 538, no. 10, pp. 156-163, 2012.

[27] W. Sun, Y. Zhu, R. Marceau et al., "Precipitation strengthening of aluminum alloys by room-temperature cyclic plasticity," Science, vol. 363, no. 6430, pp. 972-975, 2019.

[28] F. Xiu-Rong, Y. Dan-Feng, and D. Jian-Hu, "The research of forging hammer with full hydraulic technique," Chinese Hydraulics and Pneumatics, vol. 34, no. 4, pp. 24-26, 2010.

[29] China Forging Association, Special Alloys and Their Forging, National Defense Industry Press, Beijing, China, 2009.

[30] B. Tang, L. Xiang, Z. Yan, H. Kou, and J. Li, "Effect of strain distribution on the evolution of $\alpha$ phase and texture for dualphase titanium alloy during multi-pass forging process," Materials Chemistry and Physics, vol. 228, pp. 318-324, 2019.

[31] J. S. Jha, P. T. Suraj, R. Singh, A. Tewari, and K. M. Sushil, "Flow stress constitutive relationship between lamellar and equiaxed microstructure during hot deformation of Ti-6Al4V," Journal of Materials Processing Technology, vol. 270, pp. 216-227, 2019.

[32] J. Toribio, J. C. Matos, and B. González, "Micro-and macroapproach to the fatigue crack growth in progressively drawn pearlitic steels at different R-ratios," International Journal of Fatigue, vol. 31, no. 11-12, pp. 2014-2021, 2009.

[33] S. L. Semiatin, V. Seetharaman, and I. Weiss, "The thermomechanical processing of alpha/beta titanium alloys," JOM, vol. 49, no. 6, pp. 33-39, 1997.

[34] M. Brun, N. Anoshkin, and G. Shakhanova, "Physical processes and regimes of thermomechanical processing controlling development of regulated structure in the $\alpha+\beta$ titanium alloys," Materials Science and Engineering: $A$, vol. 243, no. 1-2, pp. 77-81, 1998. 
[35] C. Leyens and M. Peters, "Titanium and titanium alloys," China Surface Engineering, vol. 23, no. 1, pp. 1-513, 2003.

[36] W. Yu, M. Li, and J. Luo, "Effect of processing parameters on microstructure and mechanical properties in high temperature deformation of Ti-6Al-4V alloy," Rare Metal Materials and Engineering, vol. 38, no. 1, pp. 19-24, 2009.

[37] M. Li, L. Hong, and J. Luo, Titanium Alloy Precision Forging, Vol. 9, Science Press, Beijing, China, 2016. 


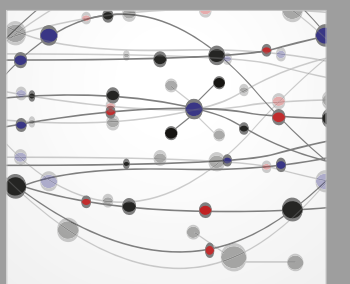

The Scientific World Journal
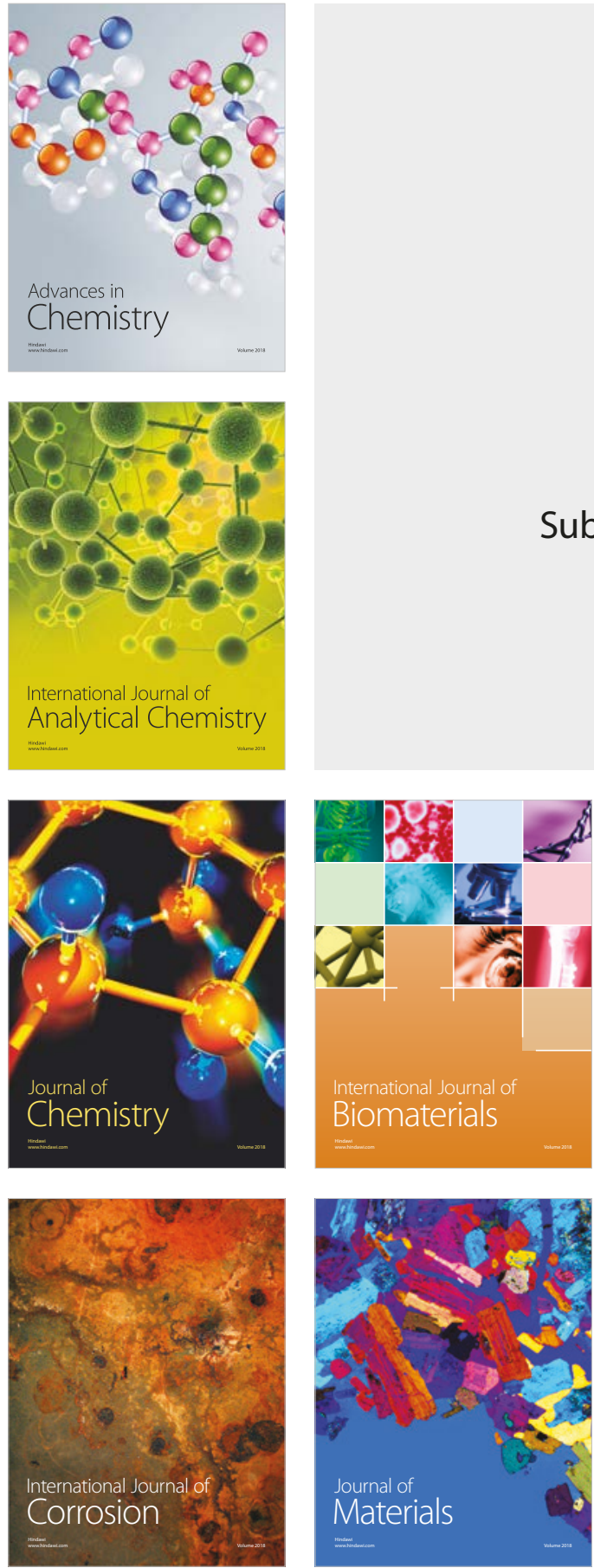

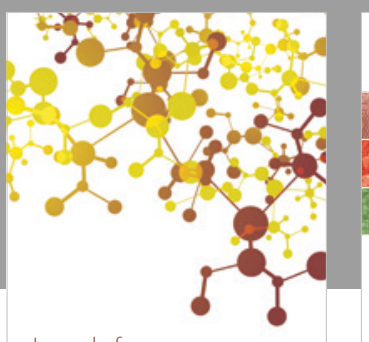

Journal of

Applied Chemistry
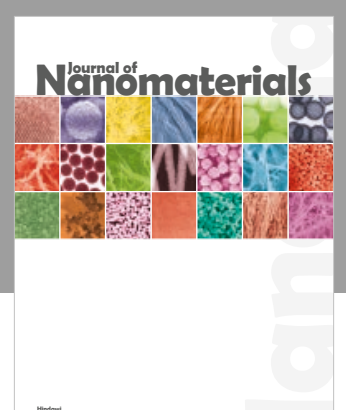

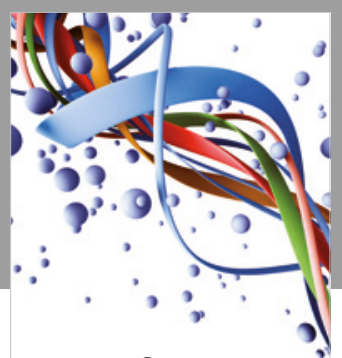

Scientifica

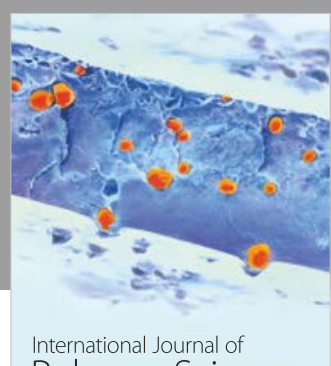

Polymer Science

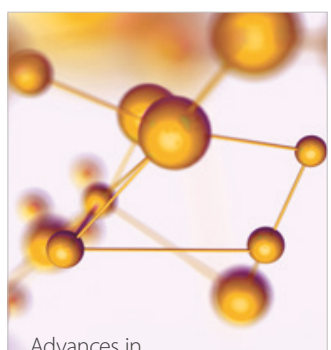

Physical Chemistry
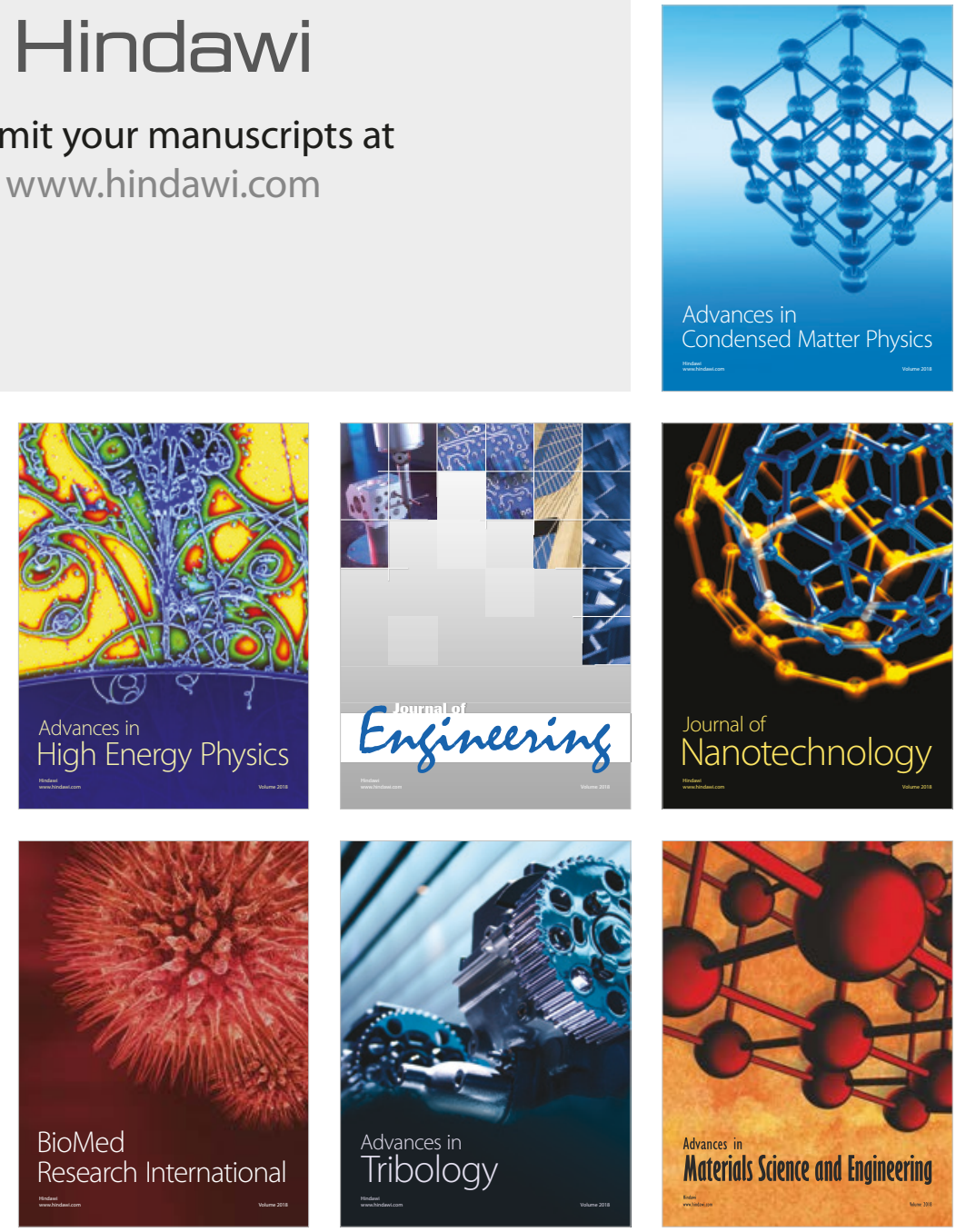